\title{
CONDIÇÃO JUVENIL E MODELOS CONTEMPORÂNEOS DE ANÁLISE SOCIOLÓGICA DAS JUVENTUDES
}

\author{
LUÍs ANTONIO GROPPO*
}

\begin{abstract}
RESUMO
Uma releitura crítica da produção da sociologia funcionalista sobre a juventude, revela concepções fundadas na idéia da «normalidade», tida como a adequação tranqüila entre a condição juvenil e a estrutura social. A «anormalidade» é aí interpretada como «disfunções», originadas da perniciosa influência de «tradições ocultas» sobre a juventude: boêmia, delinqüência e radicalismo. Nos anos 1960, reconsidera-se tal interpretação, e uma visão mais generosa sobre as revoltas juvenis permite vê-las até mesmo como possibilidade de reforma e revolução das sociedades em crise. A partir dos anos 1970, uma tendência importante foi conceber a juventude mais como «estilo de vida» que etapa do curso da vida, e os comportamentos em conflito com os valores sociais hegemônicos mais como «culturas juvenis» que rebeldias. Aparentemente, teriam sido superados os modelos clássicos explicativos da revolta juvenil. Entretanto, diversos movimentos e revoltas protagonizadas por jovens recentemente parecem demandar estes modelos supostamente superados.

PALAVRAS CHAVE: SOCIOLOGIA DA JUVENTUDE, CONDIÇÃO JUVENIL, IDENTIDADES

* Pesquisador do Conselho Nacional de Pesquisa e Desenvolvimento Tecnológico (CNPq), Brasil. Professor do Centro Universitário Salesiano de São Paulo (Unisal) e do Centro Universitário Adventista de São Paulo (Unasp). Doutor em Ciências Sociais pela Universidade Estadual de Campinas. Correo electrónico: luis.groppo@am.unisal.br.

Este artigo se baseia na segunda parte do trabalho apresentado por mim ao $30^{\circ}$ Encontro Anual da Associação Nacional de Pesquisa e PósGraduação em Ciências Sociais (ANPOCS), em Caxambu, 2006, com o título «A condição juvenil e as tradições ocultas da juventude».
\end{abstract}




\title{
CONDICIÓN JUVENIL Y MODELOS CONTEMPORÁNEOS DE ANÁLISIS SOCIOLÓGICO DE LAS JUVENTUDES
}

\begin{abstract}
RESUMEN
Una relectura crítica de la producción de la sociología funcionalista sobre la juventud revela concepciones fundadas en la idea de la «normalidad», entendida como la adecuación tranquila entre la condición juvenil y la estructura social. La «anormalidad» es interpretada como «disfunciones», originadas de la perniciosa influencia de «tradiciones ocultas» sobre la juventud: bohemia, delincuencia y radicalismo. En los años 60 se reconsidera esta interpretación, y una visión más generosa sobre las revueltas juveniles permite verlas como posibilidad de reforma y revolución de las sociedades en crisis. A partir de los año 70, una tendencia importante fue concebir la juventud más como «estilo de vida» que etapa del curso de la vida, y los comportamientos en conflicto con los valores sociales hegemónicos más como «culturas juveniles» que rebeldías. Al parecer, habrían sido superados los modelos clásicos explicativos de la revuelta de la juventud. Sin embargo, diversos movimientos y revueltas protagonizados por jóvenes recientemente parecen demandar a estos modelos supuestamente superados.
\end{abstract}

\footnotetext{
PALABRAS CLAVE: SOCIOLOGÍA DE LA JUVENTUD, CONDICIÓN JUVENIL, IDENTIDADES
}

\section{THE YOUTH CONDITION AND CONTEMPORARY MODELS OF SOCIOLOGICAL ANALYSIS OF YOUTH}

\begin{abstract}
A critical re-reading of the production of funcionalist sociology based upon youth, reveals conceptions founded on the idea of «normality», understood as the calm adjustment between the youthful condition and the social structure. "Abnormality» is interpreted as «dysfunctional», originated from the pernicious influence of «occult tradition» on youth: bohemian, delinquency and radicalism. In the 60 's this interpretation is re-considered, and has a much more generous vision on the youthful revolts which allows to see this as a possibility of reformation and revolution of the societies in crisis. As the 70's, an important tendency was to conceive youth more as a «life style» than a stage of the course of life, and the behaviors in conflict with the hegemonic social values, more like «youthful cultures» than revolts. Apparently, the explanatory classic models of the revolt of youth would have been surpassed. Nevertheless, diverse movements carried out by young people recently seem to demand that these models have supposedly been surpassed.
\end{abstract}

KEY WORDS: YOUTH SOCIOLOGY, YOUTH CONDITION, IDENTITIES 


\section{SUB-CULTURAS, ESTILOS DE VIDA E DIFERENÇAS}

ClASSICAMENTE, FORAM DOIS OS principais modelos sociológicos de análise da juventude e da rebeldia juvenil, que parecem caracterizar os modos «modernistas» de conceber a condição juvenil. ${ }^{1}$ O primeiro, o funcionalista, assentava-se no paradigma da integração social e em categorias explicativas como função e disfunção social. Neste, as rebeldias juvenis eram (e são) tidas como «disfunções», sendo a rebeldia mais característica a «delinqüência». O segundo, o modelo da moratória social, assentava-se em paradigmas reformistas e desenvolvimentistas de transformação social, com forte tendência de considerar as rebeldias juvenis como um impulso à transformação social e tomando como rebeldia mais marcante o «radicalismo».

Mas, a partir dos anos 1970, interpretações sócio-históricas de diversas origens vieram a pôr em causa mais seriamente os modelos de explicação das revoltas de juventude advindos do funcionalismo e da tese da «moratória social», entre as quais:

i) As concepções "pós-modernistas»: por exemplo, na interpretação de David Harvey (1992), apesar deste não crer que realmente o mundo ocidental passou a ser composto de sociedades "pós-modernas", certamente modificou-se o sentido da «modernização», principalmente a forma capitalista de acumulação, que deixou de ser fordista e se tornou «flexível». Neste sentido, concepções e vivências sociais do tempo e espaço passam a ser transformadas. Passamos, com a fase flexível, a uma nova compressão do espaço-tempo, radicalizando a experiência já vivida e expressa pelos modernistas. A vivência do imediato, a vigência do instantâneo - tendências marcantes no modo de sentir o tempo e o espaço pelas juventudes modernas-, segundo estas concepções, passam a ser as formas hegemônicas de sensibilidade social para todas as idades.

ii) O «embaralhamento» da infância e maturidade: a influência das mídias eletrônicas, segundo Meyrowitz (1985) e Postman (1999), teria provocado — notadamente na segunda metade do século $\mathrm{XX}$ - o embaralhamento dos atributos e status modernamente relacionados à infância e à maturidade.

iii) A juvenilização da vida: identifica-se esta temática a partir da obra de Baudrillard (1972, 1991; cf. Santos, 1992), na qual a

1 Esta discussão foi realizada na primeira parte do trabalho citado (Groppo, 2009). 
juventude, como vivência real, identidade sóciocultural efetiva e símbolo carregado de possibilidades de ruptura histórica e contestação, é recodificada como «juvenilidade», isto é, torna-se um «signo», esvaziado de sentidos autênticos produzidos pela vivência social concreta. A juvenilidade passa mesmo a determinar aos indivíduos a maneira mais legítima de vivenciar o que seria a juventude, a partir do consumo de dados produtos e atitudes indicados pela «sociedade de consumo».

iv) A reprivatização do curso da vida: segundo diversos autores da psicologia social e antropologia, houve nas últimas décadas uma «reprivatização do curso da vida», concomitantemente à «desinstitucionalização das categorias etárias». (Kohli; Meyer, 1986; cf. Debert, 1994, 1999). Os indivíduos teriam cada vez mais o direito (ou a obrigação) de comporem segundo suas próprias vontades (e condições) o curso de suas vidas. Flexibilizam-se as normas oficiais e as interferências institucionais sobre a passagem pelas idades da vida.

Entre as muitas conclusões advindas destas novas concepções, destaca-se a idéia de que as categorias etárias se tornam cada vez mais «estilos de vida». A juventude torna-se uma parte da vida humana que constitui uma identidade cultural própria, muito mais que uma «fase» passageira. Segundo Anthony Giddens, «[...] os adolescentes querem ser desassociados da idéia de que estão numa fase passageira e indefinida», buscando, ainda que inconscientemente, «[...] dar à sua cultura um caráter permanente». (apud Colombo, 2000:30).

Dois movimentos dentro da reflexão das ciências sociais sobre a condição juvenil são aí observados: i. A tentativa de superação da idéia da juventude como socialização ou preparação para a vida adulta, substituída pela idéia de que a juventude se torna um «estilo de vida» em si mesmo. ii. A tentativa de repensar os modelos modernos de rebeldia juvenil —boêmia, delinqüência e radicalismo—, que são reinterpretados como «culturas» ou «sub-culturas» juvenis. Neste segundo movimento, mais que disfunção e desvio (conforme concebia o funcionalismo), mais que rebeldia ou revolta (conforme mais generosa interpretação dos anos 1960), tem-se a construção de identidades e a produção de diversidade sóciocultural.

A clássica tese da moratória juvenil reunia, de modo pouco consciente, as duas dimensões do que chamarei abaixo da concepção dialética da condição juvenil (condição que congrega o duplo movimento de integração social e autonomia juvenil). Na tese da 
moratória juvenil, tentava se acomodar e neutralizar a dialética da condição juvenil, fazendo com que o termo positivo da tese, qual seja, a Experimentação, fosse vivida nos limites da moratória juvenil (a Separação). A Separação é o elemento integrador que mal esconde suas raízes no funcionalismo, preocupado em formar o adulto do futuro ainda com base no adulto do presente. A Experimentação, contudo, contém o elemento da autonomia, um aspecto atrativo da juventude e a se viver no momento presente.

Assim, tal qual a juventude como «direito social», a juventude como Experimentação é uma outra maneira de descrever o lado positivo do modelo da moratória juvenil, a qual indica algo fundamental na condição juvenil, tanto a moderna quanto a contemporânea (para alguns, "pósmoderna»). Trata-se da possibilidade da juventude ser vivida, nos termos de Marialice Foracchi (1972), inspirada em Mannheim (1961), como uma vinculação experimental com a realidade e os valores vigentes.

Os modelos oriundos dos estudos culturais e sociais das identidades juvenis vão, na minha avaliação, enfatizar apenas este aspecto da condição juvenil —a da Experimentação—. Neste sentido, a criação sóciocultural (como identidades autônomas e sub-culturas) seria obra quase tão somente de indivíduos e pequenos grupos diferenciais. Do mesmo modo, o tempo presente é o único relevante a partir de agora para entender a condição juvenil. No limite, considerando as teses da flexibilização dos comportamentos, a vida toda passa a ser a de uma constante experimentação e adequação permanente a um mundo mutaMes a principal crítica a ser feita a estes modelos, ainda que não a aprofunde aqui, se refere aos seus limites metodológicos. Tais estudos fazem constantemente uso de abordagens fenomênicas sobre as relações entre os jovens e a sociedade. Resulta tal em análise sem a necessária abrangência histórica, dados os limites deste modo de análise microsociológico, que tem dificuldades de alçar a sua visão para além do individual, do particular, do cotidiano.

Se Erikson (1987) falava da juventude como período coroado pela definição de uma identidade adulta, como uma moratória social em que os indivíduos poderiam e deveriam ensaiar diversos papéis, em busca de sua própria personalidade estável e consolidada, entretanto, os estudos sócioculturais passaram cada vez mais a falar de identidade juvenil ou, melhor, de identidades juvenis: a identidade passa a definir um conjunto de traços mais ou menos coerente e relativamente estável, adotado por um grupo e seus membros; os indivíduos em geral (e não apenas os jovens) passam a adotar diversas 
identidades na pós-modernidade assim como os jovens ensaiavam papéis durante o período da moratória nos idos da modernidade.

Acredito que os modelos "pós-modernistas» retiram sua lógica justamente desta exacerbação de um pólo do modelo da moratória juvenil. Na verdade, mesmo os defensores da tese da moratória anteviram esta possibilidade - a da autonomia juvenil buscar sua plenitude-, mas consideraram-na como algo indesejável, revelador de «anomia» social. Por exemplo, Furter (1967) falava de tendências em que a juventude e os movimentos juvenis desejariam construir um mundo para eles próprios, ${ }^{2}$ graças à inércia da sociedade conformista e tradicionalista, e que o correto seria constituir um mundo em separado para a juventude —ainda que com pontos de contato com o mundo «oficial»—, na qual se constituiria aquela personalidade moralmente consolidada capaz de renovar o sistema social quando adulta. Entretanto, justamente a tendência foi a dos grupos juvenis criarem seus próprios mundos e de que estes mundos passassem a ser cada vez mais valorizados pela «sociedade de consumo», pela indústria cultural - gestando a juvenilização da vida, como se descreveu no início deste artigهAichel Maffesoli (1987) é um exemplo daquela grande exaltação da "potência da socialidade», cuja «centralidade subterrânea informal» vinha, «através da abstenção, do silêncio, e da astúcia» opor-se «ao Poder do econômico-político». (p.7, grifo do autor). A espontaneidade da socialidade humana engendraria as respostas positivas e criativas diante das tendências negativas e repressoras da grande sociedade e dos amplos processos históricos. Para Maffesoli, diante da massificação, da imposição de uma «sociedade de massas», os indivíduos e pequenos

2 O próprio Erikson anteviu este processo, ainda que de modo muito negativo, tal como outros pensadores moderados de seu tempo que defendiam a necessidade de sublimar a tendência juvenil de crer-se bastar em si mesma: «Hoje em dia [...] nós enfrentamos jovens que ocultam sua verdadeira identidade - em todo o sentido da palavraatrás de uns óculos escuros e de uma cabeleira onipresente, fazendo ostentação ao mesmo tempo de uma identidade negativa com freqüência para além de seus recursos emocionais». (1987:153, texto original de meados dos anos 1960). Inclusive pensadores menos moderados, como o marxista Henri Lefevbre (1969), perceberam esta tendência e a criticaram: «Muitas pessoas jovens (parece) não querem saber o que as precederam. Uma tendência natural torna-se decisão. Eles decidem, os jovens, colocar entre parênteses e ignorar o anterior. O mundo começa com eles de um puro começo» (1969:190). 
grupos respondiam com o tribalismo, o vitalismo e a afetividade.

Maffesoli, assim como muitos daqueles que enfatizam a potência da espontaneidade de indivíduos e tribos, em contrapartida a esta ênfase, vem reificar, tornar estranho e externo aos indivíduos e seus grupos de identidade os processos históricos e as estruturas sócioeconômicas e políticas. E mais, tais processos e estruturas parecem simplesmente impor-se aos indivíduos, tendo um desenvolvimento imponderável ao qual simplesmente devemos nos adaptar e aproveitar alguns poucos espaços não preenchidos para constituir tribos afetivas e identitárias. Se Maffesoli fala da massificação, mais recentemente a preferência é ressaltar a complexificação e a mutação constante da sociedade, economia e tecnologia, as quais vêm exigir dos indivíduos tão somente adaptação permanente e fixação no tempo presente. Em resposta, nunca em oposição, indivíduos e pequenos grupos estariam criando e recriando identidades, as quais fornecem pequenos portos seguros para o eu diante de um mundo em intensa volatibilidade.

O artigo de Krauskopf (2004) me parece ser um bom indicador tanto dos aspectos positivos desta crítica culturalista ou "pósmoderna» ao modelo da moratória juvenil, quanto dos seus limites. Entre os aspectos positivos, primeiro, absorve da tese da moratória juvenil a concepção da juventude como relação experimental com os valores e a realidade. Segundo, contribuindo para desvelar um grave problema do modelo da moratória juvenil —que concebia de modo homogêneo o modo como se vive a condição juvenil—e realçando a grande qualidade dos estudos sócio-culturais recentes sobre a juventude, Krauskopf demonstra a diversidade dos modos de viver a juventude, inclusive (o que infelizmente não é o mais comum neste enfoque) relacionando a diversificação das juventudes não apenas com as opções culturais e idiossincrasias, mas também com as dificuldades provocadas pela desigualdade sócio-econômica.

No entanto, a realidade sócio-econômica-cultural é tida por Krauskopf, assim como para tantos outros que se debruçam sobre estas questões, como um complexo imponderável de processos de fragmentação. O capitalismo, em suas estruturas e processos, não é tomado como categoria que poderia explicar estes mecanismos de fragmentação e complexificação. Não se leva tão a sério, ao contrário do que poderia ser feito, que os novos desdobramentos do modo de vida e produção capitalista vêm, justamente ao aprofundar a lógica de acumulação e exploração, reforçar estas tendências de fragmentação e 
compressão do espaço-tempo social. Enfim, a realidade política, mais propriamente estatal, na relação com os jovens, é vista tão somente como «reativa». Dela se aponta tão somente sua face repressiva, reagindo rispidamente às tentativas das juventudes buscarem autonomia, diferenciação e identidade.

A realidade sócioeconômica, tecnológica e política é vista de modo dual, no fim. Ao mesmo tempo em que é algo imponderável, da qual os seres humanos não podem participar de sua construção e destino, apenas se adequar para tentar sobreviver, ela é repressora, castradora, negativa e homogeneizadora. A verdadeira realidade humana parece viver, então, em outros lugares, nos interstícios dos sistemas, onde e quando os indivíduos podem formar pequenas tribos e criar espontaneamente identidades diferenciais nas quais se sentem acolhidos.

Outras formas de conceber a realidade social e a sua relação com os indivíduos poderiam ser levadas em conta. Uma delas, muito valiosa, e que não deixa de considerar aspectos muito importantes ressaltados por estes modelos da identidade juvenil, pode conceber ambos os fatores - sistema e indivíduos - como parte de uma totalidade que se articula de modo dialético, contraditório. Ainda que com inesperados pontos de integração, inclusive onde se depositava a única esperança de fuga para os modelos de identidade. Trata-se da confluência entre o cultivo de «estilos de ser» alternativos e diferenciais e as esferas de consumo - especialmente a produção cultural- em fase de flexibilização, que encontraram o meio de recuperar sua lucratividade e multiplicar sua acumulação não mais na massificação, mas sim no atendimento e cultivo de mercados multi-segmentados.

\section{CONDIÇÃO JUVENIL}

De modo esquemático, podemos dizer que ambos os modelos clássicos, o funcionalista e o da moratória social, conceberam, de modo mais característico, a condição juvenil principalmente como uma criação das instituições e processos sociais. Isto é mais patente no funcionalismo, é claro, em que as rebeldias juvenis eram tidas menos como criatividade e protagonismo, e mais como fruto de tendências irracionais da natureza e/ou de «tradições ocultas» oriundas de estágios inferiores e/ou disfuncionais da vida social. Mas o modelo da moratória social também tendia a ver a juventude como obra da «sabedoria social», que reservou tempo e espaços especiais para que os jovens pudessem ensaiar e experimentar papéis sociais e novos 
valores. Assim, em ambos, na definição da «condição juvenil», a parte «forte» da relação entre sociedade (como instituições, estruturas e processos sóciohistóricos) e juventude (como indivíduos e grupos juvenis) caberia à sociedade.

Uma alternativa a este esquema da condição juvenil seria simplesmente inverter a relação. Muitos dos modelos «pósmodernistas» de análise das juventudes podem assim ser caracterizados, no meu entender. Nestes, a condição juvenil, ou melhor, as condições juvenis se constituem por si mesmas a partir da livre composição de elementos sociais e culturais disponíveis. A parte forte da relação sociedade-juventude é, aqui, a juventude.

Uma outra alternativa ao esquema «modernista» da condição juvenil é considerar ambos os fatores, sociedade e juventude, como importantes. Assim, seria a «relação» entre eles quem configuraria a condição juvenil. Tal alternativa me parece mais interessante que as anteriores. Mas ela poderia decair em uma variação mais sofisticada do funcionalismo, o pensamento "sistêmico», em versões como as de Niklas Luhmann. O esquema «sistêmico» da condição juvenil poderia apregoar que os fatores na relação tendem ao «equilíbrio», à recíproca acomodação.

Minha proposta, descrita abaixo, parte do suposto de que a condição juvenil se configura mesmo a partir de uma relação entre sociedade versus indivíduos e grupos juvenis. Entretanto, esta relação é dialética, ou seja, fundada numa contradição entre o movimento da integração/socialização e o movimento da autonomia/criatividade. Dito de outro modo, a condição juvenil é dialética porque está assentada sobre uma relação de contradição entre sociedade e juventudes. Esta contradição se expressa historicamente em ações de institucionalização da juventude seguidas ou precedidas de ações ou resistências dos indivíduos e grupos que são considerados ou se

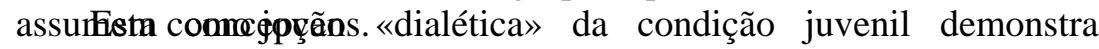
trajetórias de indivíduos e grupos juvenis oscilando no duplo movimento que envolve integração versus inadaptação, socialização versus criação de formas de ser e viver diferentes, papéis sociais versus identidades juvenis, institucionalização versus informalização, homogeneização versus heterogeneidade e heterogeneização, cultura versus sub-culturas etc. Pode-se, deste modo, interpretar que desde o início do "percurso» das juventudes na modernidade houve possibilidades e concretas ações de protagonismo juvenil, criação de identidades diferenciadas, resistências e sub-culturas (Groppo, 2004). 
Diversas rebeldias e mobilizações juvenis, pelo menos desde o Movimento Juvenil Alemão, na virada do século XIX ao XX, seguidos por movimentos estudantis diversos, movimento hippie e outros, ao longo do século XX, já traziam de modo consciente e patente o desejo desta identidade juvenil autônoma, vontade que costumeiramente pautou as suas ações sociais (Groppo, 2000).

Assim, as rebeldias, identidades autônomas e sub-culturas juvenis não são uma realidade efetiva apenas da era «pós-moderna». Põem-se em causa, assim, ao menos no que se refere às juventudes, diversas versões pós-modernistas que afirmam que a "pós-modernidade», precedida pela era da integração social homogeneizadora (a «modernidade»), assistiria solitariamente o irromper das sub-culturas e identidades auto-construídas. Também, considera-se que não são as identidades juvenis autônomas a única «verdadeira realidade» da condição juvenil, seja de modo absoluto —algo menos defensável—, seja de modo relativo, no sentido de que historicamente elas surgiriam sempre primeiro, precedendo necessariamente a intervenção social sobre as juventudes. Coloca-se em causa, agora, a tendência a considerar a rebeldia como a única e genuína «ação social», cabendo ao sistema social apenas o papel de «reação», já que, na concepção acima descrita de condição juvenil, ambos — sistema social e juventudes - podem aparecer diversamente na condição de atores e espectadores, sujeito e objeto, protagonistas e reagentes, interventores e resisteentess. modelos «pós-modernistas» contribuem muito para percebermos o movimento de autonomia, rebeldia e criação sóciocultural (ora reais, ora apenas possíveis) no interior da contraditória condição juvenil, um ponderado olhar sobre os modelos clássicos de explicação sociológica pode ajudar a entender o outro movimento que constitui a dialética vigência das juventudes modernas e confemponâm,ęss. modelos modernos e pós-modernos apresentam os dois pólos em oposição no interior da condição juvenil na modernidade e contemporaneidade. Do modelo funcionalista e da parte segregacionista da tese da moratória juvenil, podemos perceber os contornos do pólo da Integração Social. Da parte relativa à Experimentação na tese da moratória e nos modelos pós-modernos, o pólo da Autonomia Juvenil.

A concepção dialética da condição juvenil procura superar a visão não-dialética a que tendem o modelo funcionalista e o pósmodernista, cada qual ao seu modo. O funcionalismo, pela ênfase quase que absoluta no pólo da integração social, considerando o que 
poderia ser traduzido como o impulso à Autonomia como disfunções, portanto, como perturbações na ordem social que tende ao equilíbrio. Os pós-modernistas, pela ênfase também exacerbada no pólo da criatividade juvenil: ora tratando a «ordem social» como realidade imponderável a quem apenas podemos nos adaptar —e, em contrapartida-, exercer a criatividade auto-redentora em alguns espaços vagos (no cotidiano e na produção cultural); ora tratando tal «ordem» apenas como Poder negativo de repressão e homogeneização, não destacando os aspectos criadores/ propositores do sistema no que se refere à condição juvenil (não necessariamente benéficos, diga-se de passagem), nem concebendo a articulação contraditória da totalidade formada entre sistema social e indivíduos.

Ao seu modo, a tese da moratória juvenil considerou estes dois pólos —integração e autonomia - ainda que tenha tentado negar a sua relação contraditória, procurando harmonizá-los nos princípios da Separação e da Experimentação, os quais buscavam normalizar as relações potencialmente conflituosas entre instituições sociais e juventudes - conflitos que iriam explodir em intensidade e generalidade-, ainda que com brevidade, nos últimos anos da década de 1900ito do que são as ações e representações juvenis explicam-se de maneira soberba através do recurso aos conceitos e modos de análise "pós-modernistas», ainda que estes tendam a fragmentar seu objeto — as juventudes—, parecendo reproduzir aquela tendência mais geral da contemporaneidade, que fragmentou a vida social. Também, se estes modelos conseguiram assim chamar a atenção sobre a diversidade das juventudes, por outro lado podem dificultar a compreensão do que há de mais geral nas heterogêneas identidades juvenis, e, principalmente, podem dificultar a percepção da relação destes construtos oriundos do que seriam as esferas criativas da vida pós-moderna (cotidiano e cultura) com as esferas pretensamente inumanas, imponderáveis e todo-poderosas (economia, tecnologia e polítida)se crer nos modelos modernistas apresentados aqui, tanto quanto nos pós-modernistas, seria difícil perceber que nas rebeldias juvenis no período anterior ao final dos anos 1960 já havia a presença concreta de processos de construção de identidades autônomas juvenis, a elaboração de sub-culturas diferenciadas e exercícios inclusive radicais de protagonismo. Ou seja, que a condição juvenil é e era, ao longo da «modernidade» e contemporaneidade, uma condição dialética, fruto da contradição posta e reposta entre instituições sociais e possibilidades de autonomia dos jovens. 
Se esta concepção dialética da condição juvenil ajuda a compreender melhor as continuidades e descontinuidades entre as rebeldias juvenis do século XX e as sub-culturas juvenis do início do século XXI, também parece servir muito bem para avaliar acontecimentos bastante recentes, como a participação muito importante de jovens nos movimentos de crítica à globalização e os aguerridos protestos no Brasil do movimento estudantil pelo passelivre (Liberato, 2006); as revoltas dos jovens dos subúrbios franceses no final de 2005 e, novamente na França, as manifestações contra a lei do «primeiro emprego» que começaram entre os estudantes, em 2006, etc.

\section{ALGUMAS TESES SOBRE A CONDIÇÃO JUVENIL NO MUNDO CONTEMPORÂNEO}

Para complementar este trabalho, desejo expor algumas teses que, apesar, de levarem este nome, tratam-se antes de hipóteses ou conclusões de caráter parcial sobre os modelos sociológicos de interpretação das juventudes e suas rebeldias, feitas a partir do que foi discutido neste texto. Vamos a elas.

i) A crítica pós-modernista colabora com a superação de modelos evolucionistas e funcionalistas que marcaram muito do pensamento social do século XX, inclusive sobre as questões das juventudes; ajuda a perceber a convivência de espacialidades e temporalidades heterogêneas no mundo contemporâneo, bem como a diversidade de juventudes e dos modos de viver a condição juvenil. Ela colabora muito ao desfetichizar modelos explicativos clássicos cuja visão homogênea e homogeneizadora da condição juvenil limitava sua capacidade analítica. Se isto era verdade na «modernidade», torna-se ainda mais marcante na contemporaneidade, em que um capitalismo baseado na acumulação flexível multiplica a fragmentação da vida social, dificultando o uso tranqüilo de modelos explicativos rígidos em demasia e que não permitam um olhar atento às especificidades de cada evento juvenil.

ii) Esta mesma crítica, porém, muitas vezes vem dificultando um olhar desde a partir das condições, processos e estruturas de caráter mais amplo e geral, principalmente as de cunho político e econômico; dificulta compreender o caráter histórico — no sentido de que a história é fruto das ações e lutas humanas concretas- das estruturas e processos sociais, que aparecem aí muitas vezes como imponderáveis, dando a entender que restaria como única alternativa de liberdade e 
criatividade de ações na esfera micro e cotidiana, por meio de produções culturais e criações identitárias.

iii) Nesta preocupante inversão — do macro ao micro, da evolução absoluta ao relativismo absoluto—, esta visão não parece perceber, ou pouco problematiza, a integração mais ou menos bem resolvida entre as tendências da «sociedade de consumo» flexível com as construções de identidades sócioculturais diferenciadas (mesmo quando alternativas e até rebeldes) (cf. Liberato, 2006).

iv) Uma revisão dos modelos «pós-modernos» de interpretação das juventudes em consonância e/ou contraponto com tendências, processos e estruturas mais gerais do capitalismo contemporâneo (em suas várias faces, flexível, global, neoliberal etc.), permitiria relacionar melhor, entre outros, identidades juvenis e flexibilização do consumo, reprivatização do curso da vida e políticas neoliberais de desregulação e de desmanche do Estado social.

v) Os modelos «clássicos» ainda têm validade, ainda que relativa, para dar conta de diversas manifestações juvenis —inclusive de rebeldia; só a prentensa justeza da tese 1 -a convivência de temporalidades e espaços na «sociedade civil mundial»— já permitiria supor esta possibilidade; mas isto se reforça pela realidade concreta de muitas ações juvenis contemporâneas de radicalismo (como a França em 2006, Movimento Passe-Livre no Brasil, movimento anti-globalização etc.) ou que misturam radicalismo com delinqüência (a revolta dos subúrbios franceses em 2005); ações rebeldes que não se explicam apenas pela criatividade subcultural ou pela construção de identidades alternaditivał. compreensão destes movimentos parece requerer a consideração de que a estrutura etária «moderna» (baseada em categorias etárias, direitos e prerrogativas mais definidos e instituições oficiais destinadas aos cuidados para com cada categoria etária) ainda é vigente para uma boa parte da população, ainda que com caráter precarizado; esta população necessita desta institucionalidade para obter proteção e socialização em fases mais sensíveis da vida, mas, principalmente, a estrutura etária «moderna» é parte da concepção social sob o curso da vida para boa parte da população — que não teria mesmo condições sócioeconômicas para uma autoconstrução absoluta de seu curso da vida - (conforme as teses da reprivatização do curso da vida, que antes parecem descrever o privilégio de uma construção mais livre do curso da vida restrito apenas a algumas classes sociais).

vii) É claro que é possível -e mesmo necessário- olhar a estrutura etária «moderna» como formas de dominação, 
disciplinarização e homogeneização artificial e forçada, mas ela também é componente de um imaginário moderno de civilização que foi —e ainda é, em parte importante- modelo e critério sobre o dever ser das relações sociais e do curso da vida; e este imaginário também se expressou e se expressa na linguagem dos direitos e da cidadania. Parte importante dos movimentos rebeldes juvenis citados na tese 5 é, mais que uma expressão da diferença, e diverso de uma busca por mais liberdade (como foram os movimentos juvenis dos anos 1960, diante da excessiva disciplinarização e homogeneização das instituições sociais modernas e tradicionais), uma luta pela igualdade, na forma da manutenção de direitos ameaçados ou da conquista de direitos ainda recusados.

viii) Tal interpretação permite aproximar a análise destas rebeldias juvenis com a análise sobre a aplicação e os efeitos das políticas de desregulação ditas —neoliberais—, em destaque o desmanche do chamado lado social do Estado e a erosão dos direitos sociais de cidadania; a confluência das análises é justamente a da «dialética das juventudes» com a precarização das instituições tradicionais e modernas de socialização e proteção de categorias etárias mais sensíixeisNa perspectiva da ação política, não se trata de desprezar a luta pela liberdade em prol da luta pela igualdade; a defesa da mobilização em prol da manutenção e recuperação de direitos sociais não significa o irrealismo nem a não desejabilidade de maior liberdade de construção do curso da vida e maior flexibilidade nas relações etárias e inter-geracionais; só que, a curto e médio prazo, a defesa da igualdade e das possibilidades de proteção de infância, juventude e velhice são provavelmente mais cruciais.

$\mathrm{x})$ Neste sentido, uma discussão importante, ainda que, segundo a tese 9 , infelizmente ainda não a mais importante, seria a de pensar a possibilidade de uma forma de vida social emancipada sem a dependência de estruturas institucionais e estatais homogeneizadoras e disciplinarizadoras, em que se permitira realmente a generalização da liberdade e flexibilidade de composição do curso da vida e a democratização das relações etárias, "privilégios» hoje restritos a poucos grupos sociais e, em geral, como função do consumo.

SÃo PAULO (BRASIL), AGOSTO 2010

RECIBIDO: AGOSTO 2010

ACEPTADO: OCTUBRE 2010 


\section{REFERÊNCIAS BIBLIOGRÁFICAS}

Abramo, Helena Wendel (1992): Grupos juvenis nos anos 80. Um estilo de atuação social. Dissertação (Mestrado em Sociologia). São Paulo: Universidade de São Paulo.

BAUDRILlARD, JEAN (1991): A sociedade de consumo. Lisboa: Edições 70.

- (1972): Para uma crítica da economia política do signo. São Paulo: Martins Fontes.

DeBert, GuITA G. (1999): A reinvenção da velhice: socialização e processos de reprivatização do envelhecimento. São Paulo: Edusp, Fapesp.

_ (1994) (org.): «Antropologia e velhice». Textos Didáticos Nº13. Campinas: IFCH/Unicamp.

Colombo, Sylvia (2000): «A longevidade da adolescência». Folha de S. Paulo, Caderno Mais. São Paulo, 21/02/2000, p. 30-1.

ERICKSON, ERIK H. (1987): Sociedad y adolescencia. México: Siglo XXI.

FORACCHI, MARIALICE M (1972): A juventude na sociedade moderna. São Paulo: Livraria Pioneira, Editora da Universidade de São Paulo.

FURTER, PierRe (1967): Juventude e tempo presente. Rio de Janeiro: Paz e Terra.

GROPPO, LUÍS ANTONIO (2009): «O funcionalismo e a tese da moratória social na análise das rebeldias juvenis». Estudos de Sociologia V. 14, No26. Araraquara: UNEP.

(2004): «Dialética das juventudes modernas e contemporâneas». Revista de Educação do COGEIME, Ano 13, №25.

- (2000): Juventude: ensaios sobre sociologia e história das juventudes modernas. Rio de Janeiro: Difel.

KoHLI, MARTin y JOHN MEYER (1986) (orgs.): «Social structure and social construction of life stages». Human Development $\mathrm{N}^{\circ} 29$.ç

KrAUSKOPF, DiNA (2004): «Comprensión de la juventud. El ocaso del concepto de moratoria psicosocial». JOVENes. Revista de Estudios sobre la Juventud, Año 8, N²1. México: IMJ.

HARVEY, DAVID (1992): Condição pós-moderna: uma pesquisa sobre as origens da mudança cultural. São Paulo: Loyola.

LiBERATO, LEO ViniciUs MAIA (2006): «Expressões contemporâneas de rebeldia: poder e fazer da juventude autonomista». Tese (doutorado em sociologia política). Florianópolis: Universidade Federal de Santa Catarina.

Mannheim, Karl (1961): Diagnóstico de nosso tempo, Rio de Janeiro: Zahar. 
MAFFeSOli, Michel (1987): O tempo das tribos. O declínio do individualismo nas sociedades de massa. Rio de Janeiro: ForenseUniversitária.

MEYROWITZ, JoshuA (1985): «The blurring of childhood and adulthood. A case study in changing roles transitions». In: No sense of place. The impact of eletronic media on social behavior. New York: Oxford University Press.

Postman, NeIL (1991): O desaparecimento da infância. Rio de Janeiro: Graphia.

SANTOS, RAFAL (1992): «A publicidade e a representação da juventude». Dissertação (mestrado em antropologia). Campinas: Unicamp. 